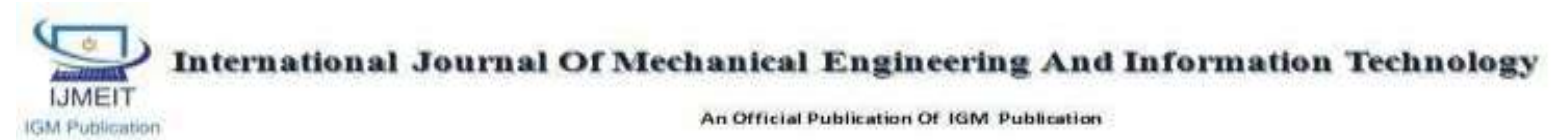

Index Copernicus Value-63.45

\title{
Determination of Optimum Parameters for Multi Performance in a Machining Process
}

\author{
Authors \\ N K Mandal ${ }^{1}$, N K Singh ${ }^{2}$, UC Kumar ${ }^{3}$ \\ ${ }^{1,3}$ National Institute of Technical Teachers' Training and Research Block- FC, Sector-III, Salt Lake City, \\ Kolkata- 700106 \\ ${ }^{2}$ Indian Institute of Technology (ISM), Dhanbad - 826004 Jharkhand
}

E mail: nkmandal@nitttrkol.ac.in, udaychandkumar@yahoo.com,nks_221@yahoo.co.in

*Corresponding Author's

N K Mandal

E-mail: nkmandal@nitttrkol.ac.in

\begin{abstract}
:
Surface roughness is a very important parameter which have direct relationship with frictional losses of the mating components. If the frictional losses is more, the machine becomes less efficient. Turning is a widely used machining process for rotational jobs where excess material is removed in the form of chips by a single point cutting tool. There are basically two types of modelling: analytical modelling and empirical modelling, Scientists are mostly believing on analytical modelling where only controllable factors of a process are taken into account and does not tell anything about uncontrollable factors like vibration, tool wear etc. whereas Engineers believe on Empirical modelling where both controllable and uncontrollable factors of a process are considered. Theoretical modelling of any machining process is based on some theoretical knowledge. Some cutting phenomena have been modelled quantitatively and others qualitatively. Heuristic knowledge and skills of machinist is still needed to optimize the machining conditions in manufacturing systems. In this case, Grey Relational Analyses are used to find out the best combination of cutting parameters for maximum surface finish and minimum power consumption.

Keywords: Turning, Power, Surface Roughness, Multi Objective Optimization, Grey Relational Analysis
\end{abstract}

\section{INTRODUCTION}

Turning centre is a special type lathe machine where multiple turning operations can be performed in a single set up. Turning is a machining operation where excess material is removed by a single point cutting tool using shear force. The turning process can be of different types like straight turning, taper turning, or exterior grooving etc. Axis motors and spindle motor which are attached to the spindle and lead screw provide power to turn the work piece at a given rotational speed, feed, and cutting speed.

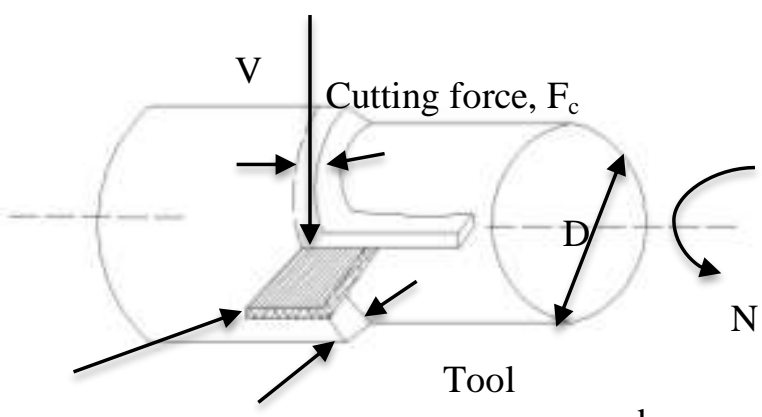

Fig. 1 Component of forces in turning operation In Fig. 1, for one revolution of the cylindrical bar, the tool moves in axial distance i.e. the feed distance (f), to reduce the bar radius by an amount of $d$ i.e. the depth of cut. The Fig. 1 also shows the cutting force $\mathrm{Fc}$ acting on the tool, the diameter D at which the cutting is taking place and both the angular speed $\mathrm{N}$ at which the bar rotates and the linear speed. The torque and power supplied by 
the axis motor. The amount of torque and power can easily be calculated from the following equation:

$$
\begin{aligned}
& T=F_{C}(D / 2) \equiv\left(F_{C}^{*} \mathrm{fd}\right)(\mathrm{D} / 2) \\
& P=F_{C} V \equiv\left(F_{C}^{*} \mathrm{fd}\right) \mathrm{V}
\end{aligned}
$$

The quantity $F_{C}^{*}$ is the cutting force per unit area of material removal called the specific cutting force. The Equation 1 indicates that a constant area of cut $f \times d$, a turning centre should be fitted with a motor with the largest capacity proportional to the largest diameter being cut. On the other hand, Equation 2 indicates that for a constant area of cut the motor power should independent of diameter of the workpiece. Generally, there are three types of power units required in a turning centre. These

are:

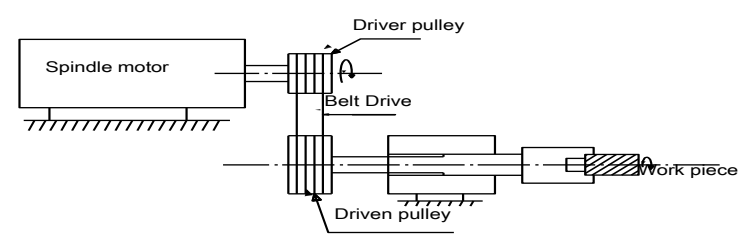

Fig. 2 Spindle drive mechanism of a turning centre

Spindle motor for running main spindle (to generate cutting speed)

Feed Motor for driving/actuating the saddles or carriages (to generate feed)

For providing power to run auxiliary services

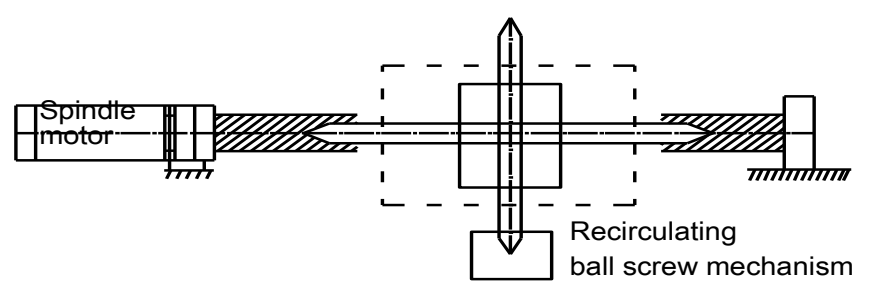

Fig. 3 Feed drive mechanism of a turning centre There are three components of cutting force in turning operation such as, main cutting force i.e. thrust force $\left(\mathrm{F}_{\mathrm{Z}}\right)$, which acts in the cutting speed direction, feed force $\left(F_{X}\right)$, which acts in the feed rate direction and the radial force $\left(\mathrm{F}_{\mathrm{Y}}\right)$, which acts in radial direction and which is normal to the cutting speed. It is assumed in different literature that about $70 \%$ to $80 \%$ of the total force $\mathrm{F}$ is used to calculate the power $\mathrm{P}$ required to perform the machining operation [Fig. 1, Fig. 2, and Fig. 3]. Power is the product of main cutting force and the cutting velocity and is the main better criterion for design and selection of spindle and feed motors. Power consumption may be used for monitoring the tool condition also. A process which removes metal at a faster rate may not be the most economical process since consumed power and cost factors must be taken into account.

Many researchers have studied the effects of optimal selection of machining parameters in turning. The machining parameters are usually selected based on either the heuristic knowledge or the proposed guidelines of the manufacturers. This selection procedure does not lead to the optimal and economically effective use of the machines and the quality of the surface generated. Sometimes, scientific methods based on Taguchi orthogonal array are used [4]. This method can analyze and provide optimum parameters for a given set of independent parameters and a response variable. If there are multiple response variables for the same set of independent variables, the methodology provides a different set of optimum operating conditions for each response variable. The grey system theory initiated by Deng [5] in 1989 has been proven to be useful for dealing with poor, incomplete, and uncertain information. The grey relational theory is adopted to determine the best process parameters that optimize response measures effectively [6]. Fong and Chen [7] presented an approach to optimize the process parameters in turning of tool steels. They performed Taguchi experiments with eight independent variables that include cutting speed, feed, and depth of cut, coating type, type of insert, chip breaker geometry, coolant, and band nose radius. The optimum turning parameters were determined based on grey relational grade that maximizes the accuracy and minimizes the surface roughness and dimensional precision. Similarly, the researchers have applied grey relational analysis (GRA) to different machining processes that include electric 
discharge machining [8], determining tool condition in turning [9], chemical mechanical polishing [10], side milling [11], and flank milling [12] to compare the performance of diamond tool carbide inserts in dry turning [13], and optimization of drilling parameters to minimize surface roughness and burr height [14]. Lin [15] used grey relational analysis to optimize turning operations with multiple performance characteristics. He analyzed tool life, cutting force, and surface roughness in turning operations. Nihat Tosun [16] reported the use of grey relational analysis for optimizing the drilling process parameters for the work piece surface roughness and the burr height is introduced. This study indicated that grey relational analysis approach can be applied successfully to other operations in which performance is determined by many parameters at multiple quality requests. Pawade and Joshi [17] used Taguchi grey relational analysis for optimizing the high speed turning parameters for surface roughness and cutting forces. Palanikumar et al. [18] optimized the turning parameters such as cutting speed, feed rate, depth of cut and machining time based on the multiple performance characteristics including material removal rate, tool wear, surface roughness and specific cutting pressure by using grey relational analysis method. Therefore, main objective of the present research is to find out best combination of input parameters for maximum surface finish with minimum power consumption.

\section{GREY RELATIONAL ANALYSIS}

Grey relational analysis is now extensively used for multi-objective optimization of a process. It is relatively simple than any other conventional process. Grey analysis is being applied in evaluating the performance of a complex project with meager information. In real world problems the situation can never be perfectly black (with no information) or perfectly white (with complete information). Situations between these extremes are described as being grey, hazy, or fuzzy. Therefore, a grey system means that a system in which a part of information is known and a part of information is unknown. Since uncertainty always exists, one is always somewhere in the middle, somewhere between the extremes, somewhere in the grey area. In the middle, grey systems will give a variety of available solutions. The relationship between machining parameters and machining performance characteristics can be found out by using the grey relational analysis. Through this analysis, the grey relational grade is favorably defined as an indicator of multiple performance characteristics for evaluation. In recent years, the grey relational analysis has become the powerful tool to analyze whether there is consistency between the changing trends of two factors or not, and to find out the possible mathematical relationship among the factors or in the factors themselves.

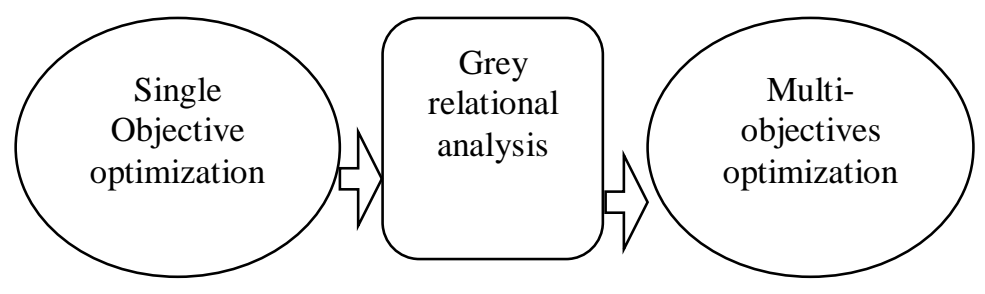

Fig. 4 Flow chart of grey relational analysis

Data preprocessing: Data preprocessing is normally required since the range and unit in one data sequence may differ from the others. Data preprocessing is also necessary when the sequence scatter range is too large or when the directions of the target in the sequences are different. Data preprocessing is a means of transferring the original sequence to a comparable sequence. Depending on the characteristics of a data sequence, there are various methodologies of data preprocessing available for the gray relational analysis. If the target value of the original sequence is infinite, then it has a characteristic of the "higher is better." The original sequence can be normalized as follows:

$$
x_{i}^{*}(k)=\frac{x_{i}^{0}(k)-\min x_{i}^{0}(k)}{\max x_{i}^{0}(k)-\min x_{i}^{0}(k)}
$$

When the "lower is better" is a characteristic of the original sequence, then the original sequence should be normalized as follows:

$x_{i}^{*}(k)=\frac{\max x_{i}^{0}(k)-x_{i}^{0}(k)}{\max x_{i}^{0}(k)-\min x_{i}^{0}(k)}$ 
However, if there is a definite target value (desired value) to be achieved, the original sequence will be normalized in from:

$$
x_{i}^{*}(k)=1-\frac{\left|x_{i}^{0}(k)-x_{i}^{0}\right|}{\max x_{i}^{0}(k)-x_{i}^{0}}
$$

Or, the original sequence can be simply normalized by the most basic methodology, i.e., let the value of the original sequence be divided by the first value of the sequence:

$$
x_{i}^{*}(k)=\frac{x_{i}^{0}(k)}{x_{i}^{0}(1)}
$$

Where $i=1 \ldots \ldots, m ; k=1, \ldots, n . m$ is the number of experimental data items, and $\mathrm{n}$ is the number of parameters. $x_{\mathrm{i}}^{\mathrm{o}}(k)$ denotes the original sequence, $x_{\mathrm{i}}{ }^{*}(k)$ the sequence after the data preprocessing, max. $x_{\mathrm{i}}^{\mathrm{o}}(k)$ the largest value of $x_{\mathrm{i}}^{\mathrm{o}}(k)$,min. $x_{\mathrm{i}}^{\mathrm{o}}(k)$ the smallest value of $x_{\mathrm{i}}^{\mathrm{o}}(k)$, and $x_{\mathrm{i}}^{\mathrm{o}}$ is the desired value of $x_{\mathrm{i}}^{\mathrm{o}}(k)$.

In gray relational analysis, the measure of the relevancy between two systems or two sequences is defined as the gray relational grade. When only one sequence, $x_{0}(k)$, is available as the reference sequence, and all other sequences serve as comparison sequences, it is called a local gray relation measurement. After data preprocessing is carried out, the gray relation coefficient $\xi_{i}(k)$ for the $\mathrm{k}^{\text {th }}$ performance characteristics in the $\mathrm{i}^{\text {th }}$ experiment can be expressed as follows

$$
\xi_{\mathrm{i}}(k)=\frac{\Delta_{\min }+\xi \cdot \Delta_{\max }}{\Delta_{o i}(k)+\xi \cdot \Delta_{\max }}
$$

Where, $\quad \Delta_{o i}(k)=\left|x_{0}^{*}(k)-x_{i}^{*}(k)\right|$ and $\Delta_{\max }=$ $1.00, \quad \Delta_{\min }=0.00$

Where, $\Delta_{o i}(k)$ is the deviation sequence of the reference sequence $x_{\mathrm{o}}{ }^{*}(k)$ and the comparability sequence $x_{\mathrm{i}}{ }^{*}(k) . \xi$ is the distinguishing or identification coefficient which is defined in the range $0 \leq \xi \leq 1$ (the value may be adjusted based on the practical needs of the system). A value of $\xi$ is the smaller, and the distinguished ability is the larger. The purpose of defining this coefficient is to show the relational degree between the reference sequence $x_{0}{ }^{*}(k)$ and the comparability sequence $x_{\mathrm{i}}^{*}(k) \cdot \xi=0.5$ is generally used.

After the grey relational coefficient is derived, it is usual to take the average value of the grey relational coefficients as the grey relational grade. The grey relational grade is defined as follows:
However, in a real engineering system, the relative importance of various factors varies. In the real condition of unequal weight being carried by the various factors, the grey relational grade in equation 6 was extended and defined as recommended by Deng (1989).

$$
\begin{aligned}
\gamma_{i} & =\frac{1}{n} \sum_{k=1}^{n} w_{k} \xi_{i}(k) \\
\sum_{k=1}^{n} w_{k} & =1
\end{aligned}
$$

Where $w_{k}$ denotes the normalized weight of factor $k$.

Here, the grey relational grade $\gamma_{i}$ represents the level of correlation between the reference sequence and the comparability sequence. If the two sequences are identical by coincidence, then the value of grey relational grade is equal to 1 . The grey relational grade also indicates the degree of influence that the comparability sequence could exert over the reference sequence. Therefore, if a particular comparability sequence is more important than the other comparability sequences to the reference sequence, then the grey relational grade for that comparability sequence and reference sequence will be higher than other grey relational grades. Grey relational analysis is actually a measurement of absolute value of data difference between sequences, and it could be used to measure approximation correlation between sequences.

\section{MATHEMATICAL MODELS OF SURFACE ROUGHNESS}

Recently a branch of science called surface science has been developed to study and analyse the surface contact area and their influence on the performance of various components, units and machines. A Surface can be described in simple turn to the outermost layer of an entity. An interface can be defined to be the transition layer between two or more entities that differ either chemically or physically or in both aspects.

Ideal Roughness: Ideal surface roughness is a function of feed and geometry of the tool. It represents the best possible finish which can be obtained for a given tool shape and feed. It can be achieved only if the built-up-edge, chatter and 
inaccuracies in the machine tool movements are eliminated completely.

Natural Roughness: In practice, it is not usually possible to achieve conditions such as those described above, and normally the natural surface roughness forms a large proportion of the actual roughness. One of the main factors contributing to natural roughness is the occurrence of a built-up edge and vibration of the machine tool. Thus, larger the built up edge, the rougher would be the surface produced, and factors tending to reduce chip-tool friction and to eliminate or reduce the built-up edge would give improved surface finish. Roughness Average $\left(R_{a}\right)$ : This parameter is also known as the arithmetic mean roughness value, AA (arithmetic average) or CLA (center line average). $\mathrm{Ra}$ is universally recognized and the most used international parameter of roughness.

$$
R_{a}=\frac{1}{L} \int_{0}^{L}|Y(x)| d x
$$

where, $R_{a}=$ arithmetic average deviation from the mean line.

$$
\begin{aligned}
& L=\text { sampling length. } \\
& Y=\text { ordinate of the profile curve. }
\end{aligned}
$$

It is the arithmetic mean of the departure of the roughness profile from the mean line.

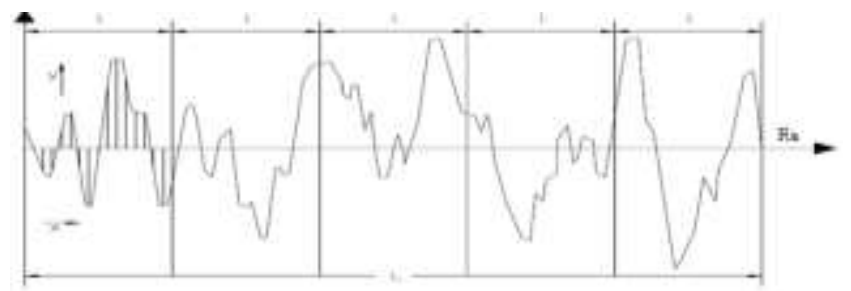

Fig. 5 Surface profile of component

\section{Experimentation}

27 no. of experiments were carried out on a CNC turning centre. The work piece material was IS: 2062, Gr. B Mild Steel bar of $24 \mathrm{~mm}$ in diameter. Commercially available HSS MIRANDA S-400 (AISI T- 42) cutting tools were used for the investigations. The percentage composition of the work piece material and cutting tool is listed in Table 1 and Table 2 respectively. Roughness is basically measure of the texture of a surface and parameter mostly used for general surface roughness is $R_{a}$. The Surface roughness $R_{a}(\mu \mathrm{m})$ of the machined samples can be measured using Mar Surf PS1 surface roughness tester and Lathe tool dynamometer was used to measure the cutting forces. The power to perform machining can be computed from equation 2. In the present experimental study, spindle speed, feed and depth of cut have been considered as machining parameters. The machining parameters with their units and their levels as considered for experimentation are listed in Table 3.

Table 1 Chemical composition of IS: 2062, Gr. B. Mild steel

\begin{tabular}{|c|l|l|l|l|l|}
\hline Material Composition & $\mathrm{C}$ & $\mathrm{Mn}$ & $\mathrm{Si}$ & $\mathrm{S}$ & $\mathrm{P}$ \\
\hline Weight Percentage (\%) & 0.15 & 0.79 & 0.22 & 0.022 & 0.030 \\
\hline
\end{tabular}

Table 2 Chemical composition of AISI T - 42 cutting tool

\begin{tabular}{|l|l|}
\hline Element & Weight percentage \\
\hline $\mathrm{C}$ & $1.25-1.40$ \\
\hline $\mathrm{Si}$ & $0.00-0.40$ \\
\hline $\mathrm{Mn}$ & $0.00-0.40$ \\
\hline $\mathrm{P}$ & 0.35 \\
\hline $\mathrm{S}$ & 0.35 \\
\hline $\mathrm{Cr}$ & $3.75-4.50$ \\
\hline $\mathrm{Mo}$ & $2.75-3.50$ \\
\hline $\mathrm{V}$ & $2.75-3.25$ \\
\hline $\mathrm{W}$ & $8.50-9.50$ \\
\hline $\mathrm{Co}$ & $9.00-10.00$ \\
\hline $\mathrm{Ni}$ & $0.00-0.40$ \\
\hline
\end{tabular}

Table 3 Machining parameters and their limits

\begin{tabular}{|c|c|c|c|c|c|}
\hline Symbol & $\begin{array}{c}\text { Machining } \\
\text { Parameter }\end{array}$ & Unit & Level 1 & Level 2 & Level 3 \\
\hline A & Spindle Speed & RPM & 160 & 240 & 400 \\
\hline B & Feed & $\mathrm{mm} / \mathrm{rev}$ & 0.08 & 0.16 & 0.32 \\
\hline C & Depth of cut & $\mathrm{mm}$ & 0.1 & 0.15 & 0.2 \\
\hline
\end{tabular}


Table 4 Experimental results

\begin{tabular}{|c|c|c|c|c|c|c|c|}
\hline $\begin{array}{l}\text { Exp. } \\
\text { No }\end{array}$ & $\begin{array}{l}\text { Spindle } \\
\text { Speed } \\
(\mathrm{RPM})\end{array}$ & $\begin{array}{l}\text { Feed rate } \\
(\mathrm{mm} / \mathrm{rev})\end{array}$ & $\begin{array}{l}\text { Depth } \\
\text { of cut } \\
(\mathrm{mm})\end{array}$ & $\begin{array}{l}\text { Response } \\
\text { main } \\
\text { force } \\
\mathrm{F}(\mathrm{N})\end{array}$ & $\begin{array}{l}\text { Cutting speed } \\
\mathrm{V}\left(\mathrm{m} \min ^{-1}\right)\end{array}$ & $\begin{array}{l}\text { Power } \\
\text { calculate }= \\
F \times V(W)\end{array}$ & $\begin{array}{l}\text { Surface } \\
\text { roughness } \\
\mathrm{R}_{\mathrm{a}}(\mu \mathrm{m})\end{array}$ \\
\hline 1 & 160 & 0.08 & 0.15 & 48 & 12.06 & 9.65 & 1.97 \\
\hline 2 & 160 & 0.08 & 0.2 & 64 & 12.06 & 12.86 & 2.01 \\
\hline 3 & 160 & 0.32 & 0.15 & 192 & 12.06 & 38.6 & 6.84 \\
\hline 4 & 160 & 0.32 & 0.1 & 87.04 & 12.06 & 17.5 & 6.16 \\
\hline 5 & 160 & 0.16 & 0.1 & 43.68 & 12.06 & 8.8 & 2.58 \\
\hline 6 & 400 & 0.32 & 0.15 & 130.56 & 30.16 & 65.63 & 5.46 \\
\hline 7 & 240 & 0.16 & 0.1 & 50.68 & 18.09 & 15.28 & 2.38 \\
\hline 8 & 400 & 0.16 & 0.15 & 70.52 & 30.16 & 35.5 & 1.68 \\
\hline 9 & 160 & 0.16 & 0.2 & 107.36 & 12.06 & 21.6 & 3.02 \\
\hline 10 & 400 & 0.16 & 0.1 & 54.68 & 30.16 & 27.5 & 2.29 \\
\hline 11 & 240 & 0.16 & 0.15 & 80.52 & 18.09 & 24.28 & 2.20 \\
\hline 12 & 400 & 0.08 & 0.2 & 64 & 30.16 & 32.17 & 1.66 \\
\hline 13 & 240 & 0.32 & 0.1 & 100.04 & 18.09 & 30.16 & 6.01 \\
\hline 14 & 240 & 0.08 & 0.1 & 25 & 18.09 & 7.54 & 1.59 \\
\hline 15 & 240 & 0.08 & 0.15 & 48 & 18.09 & 14.47 & 1.80 \\
\hline 16 & 160 & 0.08 & 0.1 & 33 & 12.06 & 6.63 & 1.88 \\
\hline 17 & 240 & 0.08 & 0.2 & 64 & 18.09 & 19.3 & 1.82 \\
\hline 18 & 160 & 0.32 & 0.2 & 174.08 & 12.06 & 35 & 6.72 \\
\hline 19 & 400 & 0.08 & 0.15 & 38 & 30.16 & 19.1 & 1.54 \\
\hline 20 & 160 & 0.16 & 0.15 & 80.52 & 12.06 & 16.2 & 3.42 \\
\hline 21 & 400 & 0.16 & 0.2 & 127.36 & 30.16 & 64.02 & 2.60 \\
\hline 22 & 240 & 0.32 & 0.15 & 192 & 18.09 & 57.9 & 5.84 \\
\hline 23 & 400 & 0.32 & 0.1 & 109.36 & 30.16 & 56 & 5.82 \\
\hline 24 & 240 & 0.32 & 0.2 & 194.08 & 18.09 & 58.5 & 6.28 \\
\hline 25 & 400 & 0.32 & 0.2 & 174.08 & 30.16 & 87.5 & 5.89 \\
\hline 26 & 240 & 0.16 & 0.2 & 127.36 & 18.09 & 38.4 & 2.84 \\
\hline 27 & 400 & 0.08 & 0.1 & 27.34 & 30.16 & 13.74 & 1.38 \\
\hline
\end{tabular}

\section{ANALYSIS OF VARIANCE (ANOVA)}

The analysis of variance (ANOVA) is used to investigate and to model the relationship between a response variable and one or more independent variables. The analysis of variance (ANOVA) was developed by Sir Ronald Fisher in the 1930s as a way to interpret the results of agricultural experiments. The purpose of the ANOVA is to investigate turning process parameters, which can significantly affect the quality characteristics. The percentage contribution in the total sum of the squared deviations can be used to evaluate the importance of the turning process parameter change on these quality characteristics. In addition, the F-test, named after Fisher, can be used to determine which machining process parameters have a significant effect on the quality characteristics. Statistically, F-test provides a decision at some confidence level as to whether these estimates are significantly different. Larger F-value indicates that the variation of the process parameter makes a big change on the performance. For a factor with a high percentage contribution, a small variation has a great influence on the performance.

Degree of freedom: Degree of freedom of factor e. $\mathrm{g}(\mathrm{df})_{\mathrm{A}}$ is one less than the number of levels $\left(\mathrm{K}_{\mathrm{A}}\right)$. The total degree of freedom of the results $(\mathrm{df})_{\mathrm{T}}$ are one less than the total number of experiments $(\mathrm{N})$. The degree of freedom for error variance $(\mathrm{df})_{\mathrm{e}}$ is 
the total degree of freedom minus sum of freedom of factors.

$$
\begin{aligned}
& (\mathrm{df})_{\mathrm{A}}=\mathrm{K}_{\mathrm{A}}-1 \\
& (\mathrm{df})_{\mathrm{T}}=\mathrm{N}-1 \\
& (\mathrm{df})_{\mathrm{e}}=(\mathrm{df})_{\mathrm{T}}-\sum(d f)_{\text {factor }}
\end{aligned}
$$

Sum of Square for any factor say A at level K was calculated according to the equation

$$
\begin{gathered}
\mathrm{SS}_{\mathrm{A}} \\
=\frac{\sum y_{0 A K}^{2}}{N}-\mathrm{S}_{m} \\
S_{m}=\frac{\left[\sum_{i=1}^{n} y_{0 i}\right]^{2}}{n}
\end{gathered}
$$

where, $S_{m}=$ sum of squares based on the mean

$$
N=\text { Repeating }
$$

number of each level of parameter.

$$
n=\text { Total }
$$

number of experiment.

$$
y_{O A K}=\text { Sum of the }
$$

$\mathrm{K}^{\text {th }}$ level of parameter $\mathrm{A}(\mathrm{K}=1,2 \ldots \ldots)$.

in the $\mathrm{i}^{\text {th }}$ experiment $(\mathrm{i}=1,2 \ldots \ldots)$.

$$
y_{0 \mathrm{i}}=\text { Value of } \mathrm{y}_{0}
$$

Total sum of square was calculated according to the equation

$$
\begin{aligned}
& S S_{T} \\
= & \sum_{i=1}^{n} y_{0 i}^{2} \\
- & S_{m}
\end{aligned}
$$

Therefore, Experimental error

$$
\begin{aligned}
& \left(\mathrm{SS}_{\mathrm{e}}\right) \\
& S S_{T}- \\
& \sum S S_{\text {factor }}
\end{aligned}
$$

Mean Sum of Square can be calculated as follows

Mean Sum of Square = Sum of square due to single factor A
Variance Ratio (F-Value) can be calculated as follows

$$
\text { Variance Ratio }(F)=\frac{\text { Mean square due to Fator A }}{\text { Error }}
$$

The Percentage Contribution can be found out from the following

Percentage Contribution

$=\frac{\text { Sum of Square due to factor }}{\text { Total Sum of Squares due to factor }} \times 100$

\section{RESULTS AND DISCUSSION}

The experimental results were analyzed using analysis of variance (ANOVA) for identifying the significant factors affecting the performance measures. The results of ANOVA for the power consumption, surface roughness of $\mathrm{Ra}$, are presented in Table 5 and Table 6 respectively. A result of ANOVA (Table 5) for the power consumption $\mathrm{P}(\mathrm{W})$ indicates that the $\mathrm{F}$ value for feed is 42.33, highest among all the $F$ values. Hence, feed is the relatively significant turning parameters affecting the overall performance characteristics followed by spindle speed $(26.05 \%)$. However, the depth of cut has least effect $(16.37 \%)$ in controlling the power consumption. Statistically, F-test decides whether the parameters are significantly different. A larger $\mathrm{F}$ value shows the greater impact on the machining performance characteristics. Larger Fvalues are observed for feed as 42.33 and spindle speed as 23.66.

Table 5 ANOVA result for power consumption $\mathrm{P}(\mathrm{W})$

\begin{tabular}{|c|c|c|c|c|c|}
\hline Parameter & $\begin{array}{c}\text { Degrees } \\
\text { of } \\
\text { freedom }\end{array}$ & $\begin{array}{c}\text { Sum of } \\
\text { square }\end{array}$ & $\begin{array}{c}\text { Mean } \\
\text { square }\end{array}$ & $\begin{array}{c}\% \\
\text { contribution }\end{array}$ & F value \\
\hline $\begin{array}{c}\text { Spindle } \\
\text { Speed } \\
\text { (RPM) }\end{array}$ & 2 & 3074.8 & 1537.405 & 26.05 & 23.66 \\
\hline $\begin{array}{c}\text { Feed } \\
\text { (mm/rev) }\end{array}$ & 2 & 5500.66 & 2750.33 & 46.6 & 42.33 \\
\hline $\begin{array}{c}\text { Depth of cut } \\
\text { (mm) }\end{array}$ & 2 & 1928.06 & 964.03 & 16.37 & 14.84 \\
\hline Error & 20 & 1299.45 & 64.97 & 11 & - \\
\hline Total & 26 & 11802.98 & - & 100 & - \\
\hline
\end{tabular}




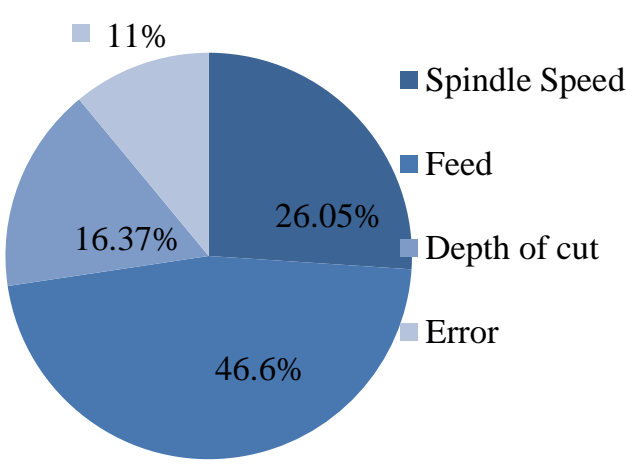

Fig. 6 Percentage of Contribution of cutting parameters in power consumption

Table 6 ANOVA result for surface roughness $R_{a}$ $(\mu \mathrm{m})$

\begin{tabular}{|c|c|c|c|c|c|}
\hline Parameter & $\begin{array}{c}\text { Degrees } \\
\text { of } \\
\text { freedom }\end{array}$ & $\begin{array}{c}\text { Sum } \\
\text { of } \\
\text { square }\end{array}$ & $\begin{array}{c}\text { Mean } \\
\text { square }\end{array}$ & $\begin{array}{c}\% \\
\text { contribution }\end{array}$ & $\begin{array}{c}\mathrm{F} \\
\text { value }\end{array}$ \\
\hline $\begin{array}{c}\text { Spindle } \\
\text { Speed } \\
\text { (RPM) }\end{array}$ & 2 & 37.23 & 18.62 & 29.4 & 32.1 \\
\hline $\begin{array}{c}\text { Feed } \\
\text { (mm/rev) }\end{array}$ & 2 & 77.37 & 38.69 & 61 & 66.7 \\
\hline $\begin{array}{c}\text { Depth of } \\
\text { cut (mm) }\end{array}$ & 2 & 0.46 & 0.23 & 0.38 & 0.39 \\
\hline Error & 20 & 11.69 & 0.58 & 9.2 & - \\
\hline Total & 26 & 126.76 & - & 100 & - \\
\hline
\end{tabular}

As seen Table 6, the influence of feed (61\%) in affecting surface roughness $\mathrm{R}_{\mathrm{a}}(\mu \mathrm{m})$ is

significantly large. The spindle speed $(29.4 \%)$ is the next significant factor. However, the depth of cut has least effect $(0.38 \%)$ in controlling the surface roughness.

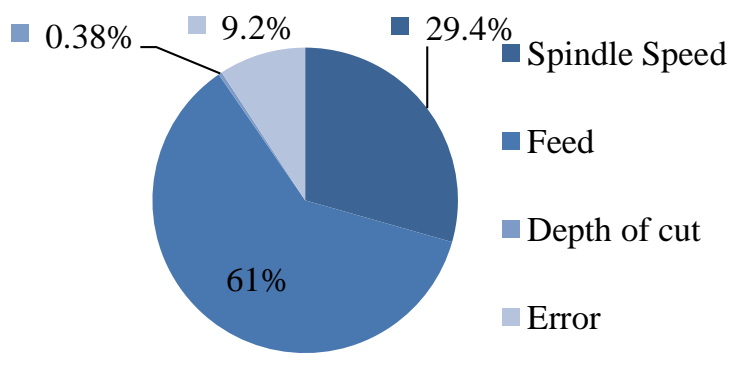

Fig. 7 Contributory percentage of cutting parameters in surface roughness
Table 7 Grey Relational Generations of Each Performance Characteristics

\begin{tabular}{|c|c|c|}
\hline Exp. No. & $\begin{array}{c}\text { Power } \\
\text { consumption } \mathrm{P}(\mathrm{W})\end{array}$ & $\begin{array}{c}\text { Surface } \\
\text { roughness } \\
\mathrm{R}_{\mathrm{a}}(\mu \mathrm{m})\end{array}$ \\
\hline $\begin{array}{c}\text { Ideal } \\
\text { sequence }\end{array}$ & 1.000 & 1.000 \\
\hline 1 & 0.693 & 0.892 \\
\hline 2 & 0.923 & 0.885 \\
\hline 3 & 0.605 & 0.000 \\
\hline 4 & 0.866 & 0.124 \\
\hline 5 & 0.973 & 0.780 \\
\hline 6 & 0.270 & 0.253 \\
\hline 7 & 0.893 & 0.817 \\
\hline 8 & 0.643 & 0.945 \\
\hline 9 & 0.815 & 0.699 \\
\hline 10 & 0.742 & 0.833 \\
\hline 11 & 0.782 & 0.850 \\
\hline 12 & 0.684 & 0.949 \\
\hline 13 & 0.709 & 0.152 \\
\hline 14 & 0.989 & 0.961 \\
\hline 15 & 0.903 & 0.923 \\
\hline 16 & 1.000 & 0.908 \\
\hline 17 & 0.843 & 0.919 \\
\hline 18 & 0.650 & 0.022 \\
\hline 19 & 0.846 & 0.970 \\
\hline 20 & 0.882 & 0.626 \\
\hline 21 & 0.290 & 0.776 \\
\hline 22 & 0.366 & 0.183 \\
\hline 23 & 0.389 & 0.187 \\
\hline 24 & 0.359 & 0.102 \\
\hline 25 & 0.000 & 0.174 \\
\hline 26 & 0.607 & 0.733 \\
\hline 27 & 0.912 & 1.000 \\
\hline
\end{tabular}

Optimal parameter combination: The workpiece surface roughness, power consumption for different combinations of turning parameters of 27 experimental runs is listed in Table 3. It is known from the analysis of machining process that the lower power consumption and lower surface roughness provide better quality of the machined surface. Thus, the data sequences of power consumption, surface roughness have "smallerthe-better" characteristics. Table 7 lists all of the sequences following data pre-processing of power consumption, surface roughness.

-Then, the deviation sequences, $\Delta_{o i}(k)=$ $\left|x_{0}^{*}(k)-x_{i}^{*}(k)\right|$ determined and are shown in Table 8. Next the Grey relational coefficient and Grey relational grade values of each experiment using full factorial design is calculated and shown 
in Table 9 and 10. Now, the multi- response optimization problem has been transformed into a single equivalent objective function optimization problem using this approach. The higher grey relational grade is said to be close to the optimal. According to performed experiment design, it is clearly observed from table which shows the change in the response when the factors go from one level to other that the turning parameters' setting of experiment no. 14 has the highest Grey relation grade. Thus, the fourteenth experiment gives the best multi-performance characteristics of the turning process among the 27 experiments.

Table 11 represents the response table for each turning parameter at different levels, respectively. As shown in Table 11, the important rank in sequence for various turning parameters in machining of mild steel.

Table 8 Evaluation of Deviation Sequence $\Delta_{o i}(K)$ For Each of the Responses

\begin{tabular}{|c|c|c|}
\hline Expt. No. & $\begin{array}{l}\text { Power } \\
\text { consumption } \\
\mathrm{P}(\mathrm{W})\end{array}$ & $\begin{array}{l}\text { Surface roughness } \\
\mathrm{R}_{\mathrm{a}}(\mu \mathrm{m})\end{array}$ \\
\hline 1 & 0.931 & 0.822 \\
\hline 2 & 0.867 & 0.813 \\
\hline 3 & 0.559 & 0.333 \\
\hline 4 & 0.789 & 0.363 \\
\hline 5 & 0.949 & 0.694 \\
\hline 6 & 0.406 & 0.400 \\
\hline 7 & 0.824 & 0.732 \\
\hline 8 & 0.583 & 0.900 \\
\hline 9 & 0.730 & 0.624 \\
\hline 10 & 0.659 & 0.749 \\
\hline 11 & 0.696 & 0.769 \\
\hline 12 & 0.613 & 0.907 \\
\hline 13 & 0.632 & 0.370 \\
\hline 14 & 0.978 & 0.928 \\
\hline 15 & 0.837 & 0.866 \\
\hline 16 & 1.000 & 0.844 \\
\hline 17 & 0.761 & 0.860 \\
\hline 18 & 0.588 & 0.338 \\
\hline 19 & 0.764 & 0.943 \\
\hline 20 & 0.809 & 0.572 \\
\hline 21 & 0.413 & 0.690 \\
\hline 22 & 0.440 & 0.379 \\
\hline 23 & 0.450 & 0.380 \\
\hline 24 & 0.438 & 0.358 \\
\hline 25 & 0.333 & 0.377 \\
\hline 26 & 0.559 & 0.652 \\
\hline 27 & 0.850 & 1.000 \\
\hline
\end{tabular}

Table 9 Grey relational coefficient of each performance characteristics for 27 comparability sequences

\begin{tabular}{|c|c|c|}
\hline Exp. No. & $\begin{array}{l}\text { Power } \\
\text { consumption } \\
\mathrm{P}(\mathrm{W})\end{array}$ & $\begin{array}{l}\text { Surface } \\
\text { roughness } \\
\mathrm{R}_{\mathrm{a}}(\mu \mathrm{m})\end{array}$ \\
\hline $\begin{array}{l}\text { Ideal } \\
\text { sequence }\end{array}$ & 1.000 & 1.000 \\
\hline 1 & 0.037 & 0.108 \\
\hline 2 & 0.077 & 0.115 \\
\hline 3 & 0.395 & 1.000 \\
\hline 4 & 0.134 & 0.876 \\
\hline 5 & 0.027 & 0.220 \\
\hline 6 & 0.73 & 0.747 \\
\hline 7 & 0.107 & 0.183 \\
\hline 8 & 0.357 & 0.055 \\
\hline 9 & 0.185 & 0.301 \\
\hline 10 & 0.258 & 0.167 \\
\hline 11 & 0.218 & 0.150 \\
\hline 12 & 0.316 & 0.051 \\
\hline 13 & 0.291 & 0.848 \\
\hline 14 & 0.011 & 0.039 \\
\hline 15 & 0.097 & 0.077 \\
\hline 16 & 0.000 & 0.092 \\
\hline 17 & 0.157 & 0.081 \\
\hline 18 & 0.350 & 0.978 \\
\hline 19 & 0.154 & 0.030 \\
\hline 20 & 0.118 & 0.374 \\
\hline 21 & 0.710 & 0.224 \\
\hline 22 & 0.634 & 0.817 \\
\hline 23 & 0.611 & 0.813 \\
\hline 24 & 0.641 & 0.898 \\
\hline 25 & 1.000 & 0.826 \\
\hline 26 & 0.393 & 0.267 \\
\hline 27 & 0.088 & 0.000 \\
\hline
\end{tabular}


Table 10 Evaluated grey relational grades for 27 groups

\begin{tabular}{|c|c|c|}
\hline Expt. No. & Grey relational grade & Rank \\
\hline 1 & 0.876 & 4 \\
\hline 2 & 0.840 & 7 \\
\hline 3 & 0.446 & 22 \\
\hline 4 & 0.576 & 18 \\
\hline 5 & 0.821 & 8 \\
\hline 6 & 0.403 & 25 \\
\hline 7 & 0.778 & 10 \\
\hline 8 & 0.741 & 12 \\
\hline 9 & 0.677 & 16 \\
\hline 10 & 0.704 & 14 \\
\hline 11 & 0.732 & 13 \\
\hline 12 & 0.760 & 11 \\
\hline 13 & 0.501 & 20 \\
\hline 14 & 0.953 & 1 \\
\hline 15 & 0.851 & 6 \\
\hline 16 & 0.922 & 3 \\
\hline 17 & 0.810 & 9 \\
\hline 18 & 0.463 & 21 \\
\hline 19 & 0.853 & 5 \\
\hline 20 & 0.690 & 15 \\
\hline 21 & 0.551 & 19 \\
\hline 22 & 0.409 & 24 \\
\hline 24 & 0.398 & 23 \\
\hline 25 & 0.355 & 26 \\
\hline 26 & 0.605 & 17 \\
\hline 27 & 0.925 & 2 \\
\hline
\end{tabular}

Table 11 Response of grey relational grade

\begin{tabular}{|c|c|l|l|l|l|c|}
\hline & \multicolumn{5}{|c|}{ Grey relational grade } \\
\hline Symbol & $\begin{array}{c}\text { Turning } \\
\text { parameters }\end{array}$ & $\begin{array}{l}\text { Level } \\
\text { I }\end{array}$ & $\begin{array}{l}\text { Level } \\
\text { II }\end{array}$ & $\begin{array}{c}\text { Level } \\
\text { III }\end{array}$ & $\begin{array}{c}\text { Max- } \\
\text { Min }\end{array}$ & Rank \\
\hline A & $\begin{array}{c}\text { Spindle } \\
\text { speed }\end{array}$ & 0.489 & $0.670^{*}$ & 0.634 & 0.181 & 2 \\
\hline B & Feed & $0.866^{*}$ & 0.699 & 0.440 & 0.426 & 1 \\
\hline C & $\begin{array}{c}\text { Depth of } \\
\text { cut }\end{array}$ & $0.733^{*}$ & 0.667 & 0.606 & 0.127 & 3 \\
\hline
\end{tabular}

[*Shows optimal turning parameters].

Total mean Grey relational grade $=0.669$. Optimum set of parameters are A in first level, B in first level and $\mathrm{C}$ in first level respectively $\left(\mathrm{A}_{2} \mathrm{~B}_{1} \mathrm{C}_{1}\right)$.

Confirmation test: After obtaining the optimal level of the machining parameters, the next step is to verify the improvement of the performance characteristics using this optimal combination.
The estimated grey relational grade using the optimum level of the 'parameters can be calculated as:

$$
\hat{\gamma}=\gamma_{m}+\sum_{i=0}^{o}\left(\overline{\gamma_{J}}-\gamma_{m}\right)
$$

Where $\gamma_{m}$ is the total mean of the grey relational grade, $\overline{\gamma_{j}}$ is the mean of the grey relational grade at the optimum level and $o$ is the number of machining parameters that significantly affects the multiple performance characteristics. Table 12 shows the results of the confirmation experiment using the optimal machining parameters. The response values obtained from the confirmation experiment are $\mathrm{P}=7.54 \mathrm{~W}, \mathrm{R}_{\mathrm{a}}=1.59 \mu \mathrm{m}$. The Power consumption $\mathrm{P}$ shows a reduced value of $9.65 \mathrm{~W}$ to $7.54 \mathrm{~W}$ and the Surface roughness $\mathrm{R}_{\mathrm{a}}$ shows a reduced value of $1.97 \mu \mathrm{m}$ to $1.59 \mu \mathrm{m}$. It is clearly shown that multiple performance characteristics in turning process are greatly improved through this study.

Table 12 Results of machining performance using initial and optimal machining parameters

\begin{tabular}{|c|c|c|c|}
\hline & $\begin{array}{c}\text { Initial } \\
\text { machining } \\
\text { parameters }\end{array}$ & $\begin{array}{c}\text { Optimal } \\
\text { machining } \\
\text { parameters }\end{array}$ & \\
\cline { 3 - 4 } & & Prediction & Experiment \\
\hline $\begin{array}{c}\text { Setting } \\
\text { Level }\end{array}$ & $\mathrm{A}_{1} \mathrm{~B}_{1} \mathrm{C}_{2}$ & $\mathrm{~A}_{2} \mathrm{~B}_{1} \mathrm{C}_{1}$ & $\mathrm{~A}_{2} \mathrm{~B}_{1} \mathrm{C}_{1}$ \\
\hline $\begin{array}{c}\text { Power } \\
\text { consumpti } \\
\text { on } \mathrm{P}(\mathrm{W})\end{array}$ & 9.65 & & 7.54 \\
\hline $\begin{array}{c}\text { Surface } \\
\text { roughness } \\
\mathrm{R}(\mu \mathrm{m})\end{array}$ & 1.97 & 0.931 & 0.953 \\
\hline $\begin{array}{c}\text { Grey } \\
\text { relational } \\
\text { grade }\end{array}$ & 0.876 & & 1.59 \\
\hline
\end{tabular}

Improvement in grey relational grade $=0.055$. It is found that the improvement of $5.5 \%$ is observed in the grey relational grade. A good agreement between the two has been observed. This ensures the usefulness of grey relational approach in relation to product/process optimization, where multiple quality criteria have to be fulfilled simultaneously. 


\section{CONCLUSIONS}

It is found that the optimum combination of turning parameters and their levels for the optimum multi-performance characteristics of turning process are $A_{2} B_{1} C_{1}$ i. e. when speed is 240 r.p.m., feed rate is $0.08 \mathrm{~mm} / \mathrm{rev}$ and depth-of-cut is $0.1 \mathrm{~mm}$. Among the tested parameters, the feed rate shows strongest correlation to power consumption and surface roughness. Confirmation test result proves that the calcuated optimum condition of turning parameters satisfies the real requirements. Thus, by properly adjusting the control factors, we can improve work efficiency and produce quality parts. Further, re researcher in might attempt to consider the other performance criteria, such as; tool wear, surface morphology of machined surface, frequency of tool vibration, MRR etc as output parameters. Different technique can also be applied for the various conventional and nonconventional machining operations to improve the performance characteristics simultaneously. In this paper an attempt has been made for the optimization of the turning process of mild steel with multiperformance characteristics based on the combined full factorial design of experiments and Grey relational analysis.

\section{REFERENCES}

1. Trent EM (1984) Metal cutting $2^{\text {nd }}$ edition. Butterworth's \& Co. London UK limited. ISBN 0-408:34-38.

2. Nagpal GR (1986) Machine Tool Engineering. Khanna Publishers, New Delhi: 68-71.

3. Kalpakjian S (2000) Manufacturing Engineering and Technology, $4^{\text {th }}$ Edition. Illinois Instotute of Technology: 545-548.

4. Phadke MS (1989) Quality Engineering using Robust Design. Prentice Hall Englewood Cliffs NJ.

5. Deng J (1989) "Introduction to grey system”. J Grey Syst 1(1):1-24.

6. Wang Z, Zhu J, and Wu (1996) Grey relational analysis of correlation of errors in measurement. J Grey System: 73-78.
7. Yih-Fong Tzeng, Fu-Chen Chen (2006) Multi-objective process optimization for turning of tool steels. Int $\mathbf{J}$ of Mach and Machina of Mater 1(1):76-93.

8. Lin JL, Lin CL (2002) The use of the orthogonal array with grey relational analysis to optimize the electrical discharge machining process with multiple performance characteristics. Inter J Mach Tools Manuf 42(2):237-244.

9. Lo sp (2002) The application of ANFIS and grey system method in turning toolfailure detection. Int $\mathrm{J}$ Adv Manuf Technol 19: 564-572.

10. Lin ZC, Ho CY (2003) Analysis and application of grey relation and ANOVA in chemical-mechanical polishing process parameters. Int $\mathrm{J}$ Adv Manuf Technol 21:.10-14.

11. Chang CK, Lu HS (2007) Design optimization of cutting parameters for side milling operations with multiple performance characteristics. Int $\mathrm{J} \mathrm{Adv}$ Manuf Technol 32(1/2):18-26.

12. Kopac J, Krajnik P (2007) Robust design of flank milling parameters based on greyTaguchi method. Int J Adv Manuf Technol 191: 400-403.

13. Arumugam Prabhu U, Malshe Ajay P, Batzer Stephen A (2006) Dry machining of aluminium silicon alloy using polished CVD diamond-coated cutting tools inserts. Surf Coat Technol 200:3399-3403.

14. Tosun N (2006) Determination of optimum parameters for multiple performance characteristics in drilling by using grey relational analysis. Int $\mathbf{J} \mathrm{Adv}$ Manuf Technol 28:450-455.

15. Lin CL (2004) Use of the Taguchi method and grey relational analysis to optimize turning operations with multiple performance characteristics. Mater Manuf Process 19:209-220.

16. Nihat T (2006) Determination of optimum parameters for multi-performance characteristics in drilling using grey 
relational analysis. Int $\mathrm{J}$ Adv Manuf Technol 28: 450- 455

17. Pawade RS, Joshi SS (2011) Multiobjective optimization of surface roughness and cutting forces in high-speed turning of Inconel 718 using Taguchi grey relational analysis (TGRA). Int $\mathrm{J} \mathrm{Adv}$ Manuf Technol 56:47-62.

18. Palanikumar K, Karunamoorthy L, Karthilesyan R (2006) Multi performance optimization of machining parameters on the machining of GFRP composites using carbide (K 10) tool. Mater Manuf Process 21:846-852. 